\title{
SPECIFIC ANOMALY DETECTION METHOD IN WIRELESS COMMUNICATION NETWORKS
}

\author{
Eva Holasová, Karel Kuchař \\ Master Degree Programme (2), FEEC BUT \\ E-mail: xholas08@vutbr.cz,xkucha24@vutbr.cz \\ Supervised by: Radek Fujdiak \\ E-mail: fujdiak@feec.vutbr.cz
}

\begin{abstract}
This paper is focused on security problems in wireless networks covering on problems of security protocols like weak cipher in WEP (Wired Equivalent Privacy), dictionary attack in WPA (Wi-Fi Protected Access) and KRACK (Key Reinstallation attack) in WPA2. The structure of KRACK attack is described. Potential solution of KRACK is handling the network traffic especially with EAPOL (Extensible Authentication Protocol over LAN) frames is described, too. As a result security consists of multiple parts and it is important to both keep and update security level on every part of the network.
\end{abstract}

Keywords: Security, WEP, WPA, WPA2, KRACK, EAPOL

\section{1 ÚVOD}

Oblast bezdrátových sítí je v soušasné době hojně využívána. Pomocí bezdrátových sítí komunikují nově i domácí spotřebiče a může být využívána internetem věcí (IoT). Stejně jako jiné komunikační sítě tak i bezdrátové sítě přenášejí citlivá data, a proto je nutné komunikaci zabezpečit. Ke komunikaci se využívá rodina protokolů IEEE 802.11, která obsahuje několik komunikačních standardů. S každým novým standardem se zvyšuje míra zabezpečení komunikace mezi jednotlivými prvky sítě. Tyto standardy jsou ale zpětně kompatibilní, což může představovat bezpečnostní riziko.

\section{EXPERIMENTÁLNÍ TESTOVÁNÍ}

Bezdrátové sítě jsou složeny z přístupového bodu, ke kterému se připojují uživatelské stanice. Tyto stanice využívají ke komunikaci vybraný standard, který definuje možné způsoby zabezpečení. Na obrázku 11 část (a), jsou zobrazeny jednotlivé vektory útoku na části bezdrátové sítě. Vektor útoku na př́stupový bod (1), vektor útoku na přenos dat (2), vektor útoku na uživatele a uživatelskou stanici (3) a vektor útoku z internetu (4). Bezpečnost bezdrátové síte je závislá na vybraném šifrovacím standardu. K provedení experimentálního testování byla sestavena experimentální sít' zobrazena na obrázku 11 část (b). Sít' je složena z přístupového bodu komunikujícího s uživatelskou stanicí. K demonstraci bezpečnostních incidentů je využita stanice s virtualizovaným operačním systémem Kali Linux. Tato stanice je dále vybavena USB Wi-Fi adaptérem pracujícím v monitorovacím režimu. K provedení experimentálního testování byly využity nástroje, které jsou součástí vybraného operačního systému Kali Linux. Aby bylo možné zachytávát veškerý sít'ový provoz, bylo využito př́íkazu airmon-ng start wlan0, který uvede bezdrátové rozhraní do monitorovacího režimu.

Experimentální testování bylo nejprve zaměřeno na bezpečnostní protokol WEP (Wired Equivalent Privacy), nutné využít standard IEEE $802.11 \mathrm{~g}$. K prolomení př́stupové fráze je nutné zachytit sít'ovou komunikaci šifrovanou pomocí WEP. K tomu je třeba získat číslo kanálu a BSSID (Basic Service Set Identifiers) př́stupového bodu. Pro výpis těchto informací je využit př́kaz airodump-ng wlanOmon. Následné zachytávání provozu je provedeno pomocí př́kazu airodump-ng -c [kanál] -bssid [mac] 


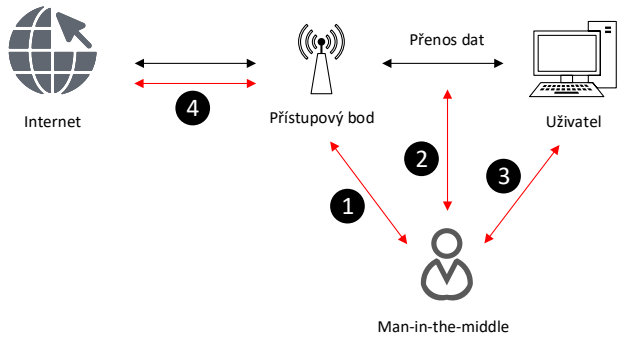

(a)

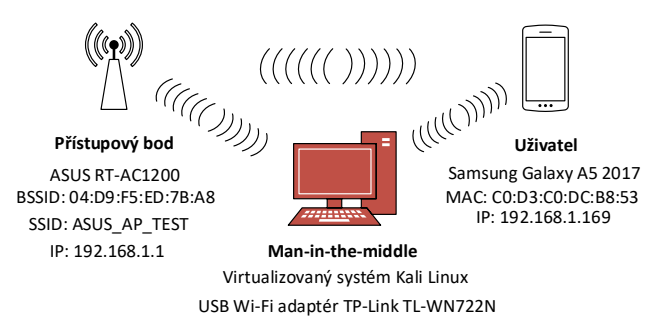

(b)

Obrázek 1: Vektory útoku (a), experimentální sít' (b) [1].

-w [soubor] wlanOmon. K fake autentizaci je využit př́kaz aireplay-ng -1 0 -a [mac] wlan0mon, kde je následně generován provoz pomocí ARP (Address Resolution Protocol) request/replay zpráv př́ikazem aireplay $-3-b[\mathrm{mac}]$ wlanOmon. Po dosažení přenesení určitého množství zpráv (minimálně 10000 vektorů) lze prolomit klíč pomocí př́íkazu aircrack-ng -O '[soubor]'.

Experimentální testování bylo provedeno obdobně pro bezpečnostní protokol WPA (Wi-Fi Protected Access). Postup je totožný, až na poslední příkaz. $\mathrm{V}$ př́ípadě WPA je nutné použít slovník, pomocí kterého bude přístupová fráze prolomena. Lze využít toho, že OS Kali Linux již obsahuje slovník "Rockyou". Poslední př́kaz bude mít podobu aircrack-ng -b [mac] -w/usr/share/wordlist/rockyou.txt [soubor].

Velkou část útoků zahajuje proces deautentizace, proto byl využit skript [2], který umožňuje detekovat deautentizační rámce, které se vyskytly v síti. Skript vyžaduje nástroj Scapy pro práci se sít'ovým provozem a nastavení Wi-Fi adaptéru do monitorovacího režimu. Výpis 1 zobrazuje výstup skritpu při zachycení deautentizačního rámce $\mathrm{s}$ cílem odpojit zařízení s MAC adresou $c 0: d 3: c 0: d c: b 8: 53$ od bezdrátové sítě.

Výpis 1: Zachycený deautentizační rámec.

[\#] Deauthentication Packet : c0:d3:c0:dc:b8:53<---> 04:d9:f5:ed:7b:a8 Packets : 1

\#] Deauthentication Packet : $04: \mathrm{d} 9: \mathrm{f} 5:$ ed:7b:a8 <---> c0:d3:c0:dc:b8:53 | Packets : 4

\section{SIMULACE ÚTOKU KRACK}

Současně používané bezdrátové standardy IEEE 802.11 pracují s protokolem WPA2 (Wi-Fi Protected Access 2). Protokol využívá k autentizaci mechanizmus 4-way Handshake. Tento protokol je ale zranitelný na útok KRACK (Key Reinstallation attack). Útočník není schopen získat př́stupovou frázi $\mathrm{k}$ bezdrátové síti, ani získat šifrovací klíč, který byl dohodnut během 4-way handshaku. Je ale schopen dešifrovat komunikaci mezi klientem a prrístupovým bodem, a tak se dostat do komunikace. Tento útok má nejvyšší dopady v případě, že obět' nepoužívá AES-CCMP (Advanced Encryption Standard - Counter Mode Cipher Block Chaining Message Authentication Code Protocol), ale WPA-TKIP (WiFi Protected Access - Temporal Key Integrity Protocol) nebo GCMP (Galois Counter Mode Protocol). Poté je možné nejen komunikaci odposlouchávat, ale i vytvářet a injektovat provoz. Aby bylo možné útok KRACK demonstrovat, bylo využito projektu [3] dostupného na [4]. Projekt obsahuje skripty, které jsou schopny detekovat, zda je sít' odolná vůči simulovanému útoku.

Na obrázku 2 část (a) je znázorněn postup útoku KRACK na 4-way handshake. Útok využívá ustanovení MITM (Man In The Middle), který přeposílá první tř̌i zprávy 4-way handshaku. Čtvrtou zprávu od klienta však nepřepošle na legitimní AP. Klient v domnění, že 4-way handshake proběhl úspěšně 
instaluje klíc relace PTK (Pairwise Transient Key) a začne posílat šifrovanou komunikaci směrem k AP přes MITM, který tuto zprávu opět nepřeposílá dále. Po vypršení časovače přijetí 4. zprávy legitimního AP, dochází k opětovnému zaslání zprávy $3 \mathrm{~s}$ inkrementovanou hodnotou replay counter (r). V reakci na tento stav dochází na klientské stanici k reinstalaci PTK klíče a odeslání zašifrované 4. zprávy. Tato zpráva je předána legitimnímu AP k dokončení 4-way handshaku. MITM nyní provede XOR operaci mezi původní 4. zprávou a šifrovanou 4. zprávou (červeně vyznačené) k získání keystreamu. Získaný keystream je využit k šifrování a dešifrování následujících zpráv (zeleně vyznačené).

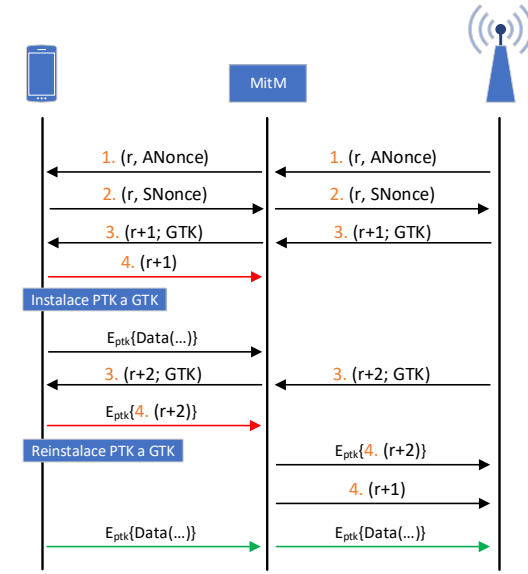

(a)

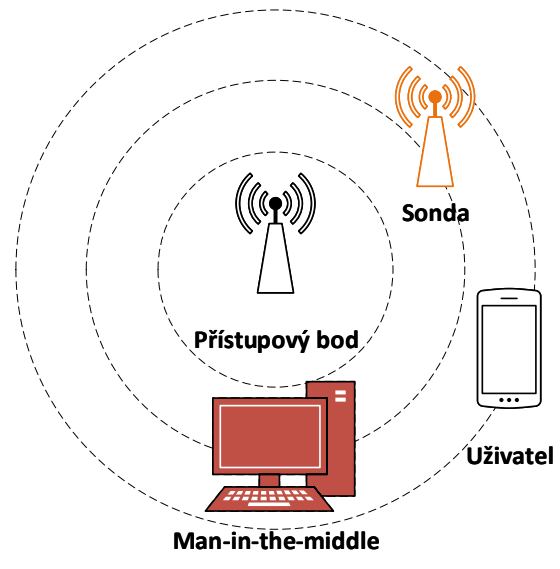

(b)

Obrázek 2: KRACK útok [3] (a), experimentální sít pro využití python skriptu (b).

K demonstraci detekce pokusu o KRACK útok bylo využito toho, že je nutné, aby legitimní AP zopakoval 3. zprávu 4-way handshaku dvakrát a tím klient po druhé vygeneroval zprávu 4, za účelem detekce bylo navrženo sít'ové zapojení zobrazeno na obrázku 2, část (b). Toto chování lze na síti detekovat pomocí sít'ového rozhraní v monitorovacím režimu. K detekci tohoto chování byl vytvořen skript využívající programovací jazyk Python. Skript využívá nástroje Scapy, který umožňuje zachytávání a následnou práci se sít'ovým provozem v režimu sondy sít'ového provozu. Pravidlo s filtrací EAPOL (Extensible Authentication Protocol over LAN) rámců, viz výpis 2 Po zachycení EAPOL rámce dojde $\mathrm{k}$ zaznamenání počtu pokusů komunikace mezi AP a klientem, výstup viz výpis 3.

Výpis 2: Zachytávání sít'ového provozu s filtrací.

Výpis 3: Výstup skriptu pro zachycení EAPOL rámců.

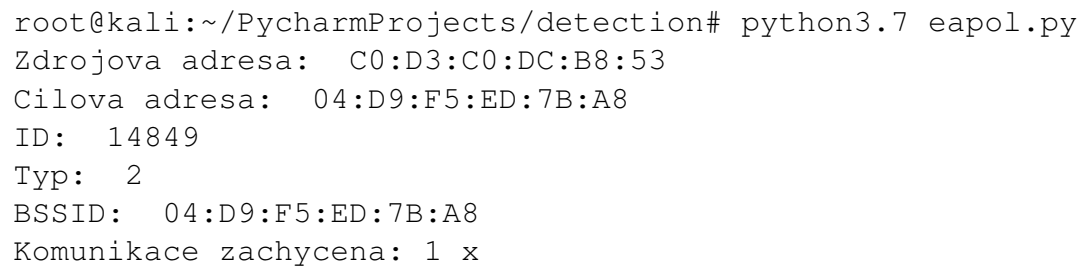

Tento skript lze dále rozšriritit o následnou deautentizaci a přimět tak obě legitimní strany opětovně provést 4-way handshake pro ustanovení nového klíče relace, viz obrázek 3 . V síti bude akceptován pouze 4-way handshake, který proběhl úspěšně na první pokus. Aby nevznikla př́ilišná zátěž sítě lze dále využít skript pro detekci zranitelnosti na KRACK útok a vyžadování 4-way handshaku na první pokus by bylo aplikováno pouze pro zařízení s potenciální zranitelností. 


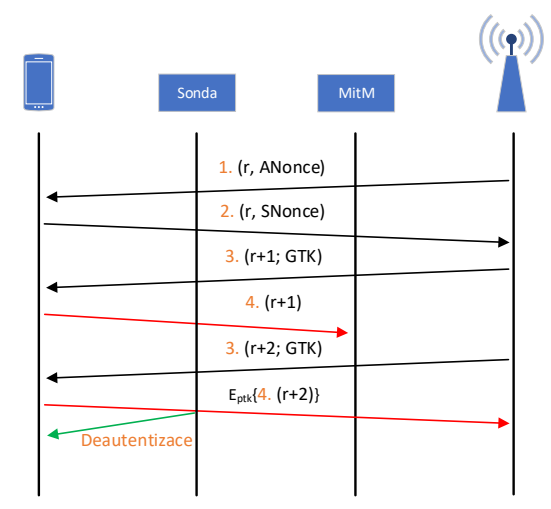

Obrázek 3: Princip skriptu detekující podruhé zaslanou čtvrtou zprávu 4-way handshaku.

\section{ZÁVĚr}

Bezdrátové sítě jsou stále více používány a je nutné udržovat jejich zabezpečení na co nejvyšší úrovni. Práce se nejprve zaměřuje na prolomení bezpečnosti WEP a WPA pomocí nástroje aircrack-ng. V protokolu WPA2 byla nalezena zranitelnost KRACK využívající chybu v 4-way handshaku. Proti tomuto útoku lze sít' chránit např́íklad pomocí detekce opětovného zaslání zprávy tř̌i a čtyři 4-way handshaku, které je představeno v této práci. Pro zvýšení bezpečnosti bezdrátových sítí lze také využít zachytávání deautentizačních rámců.

Velkou výhodou a zároveň nevýhodou bezdrátových sítí je jejich volné šîrení prostorem. Pro adekvátní zabezpečení je nutné dbát jak na uživatelskou část zabezpečení, tedy definovat určité požadavky na vytvořené heslo, tak i na zabezpečení poskytnuté samotným standardem. Pro zabezpečenou sít' je vhodné nastavit nejsilnější úroveň zabezpečení, zvolit silnou př́istupovou frázi a umístit do sítě IDS/IPS (Intrusion Detection System/Intrusion Prevention System) systém, nebo WIDS/WIPS (Wireless Intrusion Detection System/Wireless Intrusion Prevention System) systém, k zaznamenání nedovoleného chování v síti. Popřípadě používání dalších skriptů ke kontrole vybraných parametrů.

\section{REFERENCE}

[1] HOLASOVÁ, Eva. Specifické metody detekce anomálií v bezdrátových komunikačních sítích [online]. Brno, 2019 [cit. 2020-02-18]. Dostupné z: https://www.vutbr.cz/studenti/zavprace/detail/123144. Semestrální práce. Vysoké učení technické v Brně, Fakulta elektrotechniky a komunikačních technologií, Ústav telekomunikací. Vedoucí práce Radek Fujdiak.

[2] Wireless_scripts: deauthentication_detector.py [online]. [cit. 2019-12-08]. Dostupné z: https://github.com/surajsinghbisht054/wireless_scripts/blob/master/deauthentication_detector.py

[3] VANHOEF, Mathy. Key Reinstallation Attacks: Breaking WPA2 by forcing nonce reuse. Key Reinstallation Attacks [online]. KU Leuven, 2017 [cit. 2019- 11-26]. Dostupné z: https://www.krackattacks.com/

[4] Krackattacks-scripts. GitHub [online]. [cit. 2019-12-17]. Dostupné z: https://github.com/vanhoefm/krackattacks-scripts 